\section{Niño con cardiopatía congénita controlada y muerte inesperada}

\section{Child with stable congenital heart disease and unexpected death.}

López-Terrazas $\mathrm{JH}^{1}$, Colín-Ortiz JL², López-Corella E

\section{RESUMEN CLÍNICO}

Niño de ocho meses de edad que llegó al Servicio de Urgencias del Instituto Nacional de Pediatría con cuadro de un día evolución con fiebre, odinofagia, vómitos y tres evacuaciones diarreicas abundantes. Falleció al día siguiente de su ingreso. Había ido al hospital donde se llevaba a cabo su manejo y en el que le administraron paracetamol, pero al día siguiente presentaba deshidratación, quejido respiratorio y saturaba 50\% al aire ambiente, por lo que los padres administraron oxígeno por puntas nasales y acudieron a este Instituto.

El niño fue producto de la tercera gesta, de madre sana de 21 años de edad y padre también sano de 28 años. Los padres son primos lejanos y una prima hermana del paciente se refiere con un soplo. Las dos gestaciones previas terminaron en abortos. Un ultrasonido sugirió cardiopatía por lo que este embarazo se atendió en un instituto especializado. Allí nació por cesárea a las 37 semanas de gestación, con peso al nacer de 2,715 g, con APGAR de 7/9; se realizaron maniobras de reanimación neonatal por aleteo nasal discreto y tiraje intercostal leve. Se identificó cardiopatía y a los cuatro días de edad fue referido a un instituto de tercer nivel. Allí se diagnosticó síndrome de ventrículo derecho hipoplásico, atresia valvular pulmonar con séptum íntegro y un conducto arterioso largo y tortuoso. A los
${ }^{1}$ División de Cirugía Cardiovascular. ¿2ervicio de Cardiología/Hemodinamia. ${ }^{3}$ Departamento de Patología.

Instituto Nacional de Pediatría, México.

Recibido: 6 de septiembre del 2016

Aceptado: 4 de octubre del 2016

Correspondencia

Dr. Javier Horacio López Terrazas

Javier_lopezt@hotmail.com

Este artículo debe citarse como López-Terrazas JH, Colín-Ortiz JL, López-Corella E. Niño con cardiopatía congénita controlada y muerte inesperada. Acta Pediatr Mex. 2016;37(6):333-340. 
quince días de edad se practicó una fístula de Blalock-Taussig. Durante ese internamiento tuvo una trombosis de vena femoral izquierda secundaria a uso de catéter que fue resuelta. Fue dado de alta en buenas condiciones, con peso de $3,090 \mathrm{~g}$ y talla de $52.2 \mathrm{~cm}$.

Cinco meses después estuvo internado cinco días en el mismo hospital con un cuadro de neumonía adquirida en la comunidad. Fue dado de alta en condiciones estables, con peso de 5,800 g y talla de $64 \mathrm{~cm}$. Estuvo asintomático un mes y medio hasta el episodio que motivó su ingreso a nuestro Instituto.

Lo recibimos saturando a $77 \%$, con frecuencia cardiaca de 170 latidos por minuto (lpm) con episodios de hasta 184 lpm, tensión arterial de $118 / 65 \mathrm{mmHg}$ y temperatura de $38.4^{\circ} \mathrm{C}$. Presentaba quejido espiratorio, cianosis generalizada y deshidratación moderada. La exploración de tórax solo consignó soplo sistólico por fístula de Blalock-Taussig y el hígado se palpó a $4 \mathrm{~cm}$ por debajo del reborde costal. Los pulsos distales fueron palpables, con Ilenado capilar de 6 segundos. La gasometría reportó pH 6.9, $\mathrm{PO}_{2} 53.5 \mathrm{mmHg}, \mathrm{PACO}_{2}$ $27.1 \mathrm{mmHg}, \mathrm{HCO} 35.2 \mathrm{mEq} / \mathrm{L}$, SAT $55 \%$, lactato $20.8 \mathrm{mmol} / \mathrm{L}$. Se administraron cargas de bicarbonato que mejoraron los parámetros $y$, por continuar con quejido espiratorio, se intubó y se instaló sonda nasogástrica y catéter venoso central.

El mismo día de su ingreso fue valorado por el Servicio de Cardiología. El ecocardiograma informó: 1) Atresia pulmonar con séptum interventricular íntegro. 2) Ramas de arteria pulmonar confluentes, rama izquierda de diámetro limítrofe. 3) Comunicación interatrial no restrictiva. 4) Anillo tricuspídeo hipoplásico. 5) Ventrículo derecho hipoplásico. 6) Fístula de Blalock-Taussig permeable. 7) Función ventricular izquierda sistólica conservada.
El paciente permanecía inestable, con tensión arterial que bajaba a $85 / 60 \mathrm{mmHg}$, tensión arterial media $47 \mathrm{mmHg}$, taquicardia de $183 \mathrm{lpm}$, polipnea y somnolencia. La biometría hemática informó hemoglobina de $9.9 \mathrm{~g} / \mathrm{dL}$, hematocrito de $30.2 \%$, 21,300 leucocitos $/ \mathrm{mm}^{3}$ con $50 \%$ de neutrófilos y $10 \%$ de bandas, plaquetas de $177,000 / \mathrm{mm}^{3}$. El Servicio de Infectología lo consideró en probable choque séptico con gastroenteritis de probable etiología bacteriana. En la interconsulta con Cuidados Intensivos Cardiovasculares se comentó que la persistencia del choque a pesar de la estabilización hídrica sugiere una causa no hipovolémica del choque; se consideró translocación bacteriana y sepsis. En la noche presentaba abdomen distendido y peristalsis disminuida. Presentaba piel marmórea y fría y acrocianosis. La placa de abdomen mostró edema interasa.

El día siguiente a su ingreso la valoración por el Servicio de Nefrología documentó choque mixto cardiogénico y séptico, anuria con elevación de azoados al $50 \%$ de lo basal; se le consideró en falla renal aguda. La distensión abdominal con ascitis y datos de enterocolitis impedían la instalación de catéter para diálisis peritoneal. Un nuevo ecocardiograma se interpretó como oclusión de la fístula de Blalock-Taussig y comunicación interatrial restrictiva.

El paciente presentaba edema generalizado, piel fría y marmórea, pupilas midriáticas no reactivas, acrocianosis con Ilenado capilar de 8 segundos. En virtud de la aparente oclusión de la fístula sistémico pulmonar y la comunicación interatrial restrictiva, pasó a estudio hemodinámico con la intención de hacer una septostomía de Rashkind. En el cateterismo se comprobó la fístula permeable con estenosis leve a moderada en el origen de la subclavia derecha. Durante el cateterismo presentó bradicardia y paro cardiaco; las maniobras de reanimación durante 30 minutos no lograron revertirlo y el paciente falleció. 


\section{COMENTARIO CLÍNICO}

\section{Dr. López Terrazas}

Este caso es de un niño de 8 meses de edad, a quien se le diagnostica prenatalmente como atresia valvular pulmonar con septum íntegro. El control del embarazo se lleva en una institución altamente especializada en el manejo perinatal, y una vez nacido, es enviado a un centro hospitalario de tercer nivel, donde se le construye una fístula de Blalock-Taussig (Figura 1) durante la primera semana de vida, dándose de alta en condiciones satisfactorias. Tuvo un internamiento en esa misma institución por cuadro neumónico, egresándose también en buenas condiciones. Finalmente acude de nuevo al servicio de urgencias de esa institución con un cuadro infeccioso gastrointestinal, lo envían a su casa con tratamiento sintomático, pero al ver los padres empeoramiento de su condición clínica, deciden acudir al servicio de urgencias de nuestra institución. Llega en muy malas condiciones, con saturación de $\mathrm{O}_{2}$ a 50\%, acidosis y datos de choque séptico, se realiza estudio clínico cardiológico, así como ecocardiografía, que corrobora

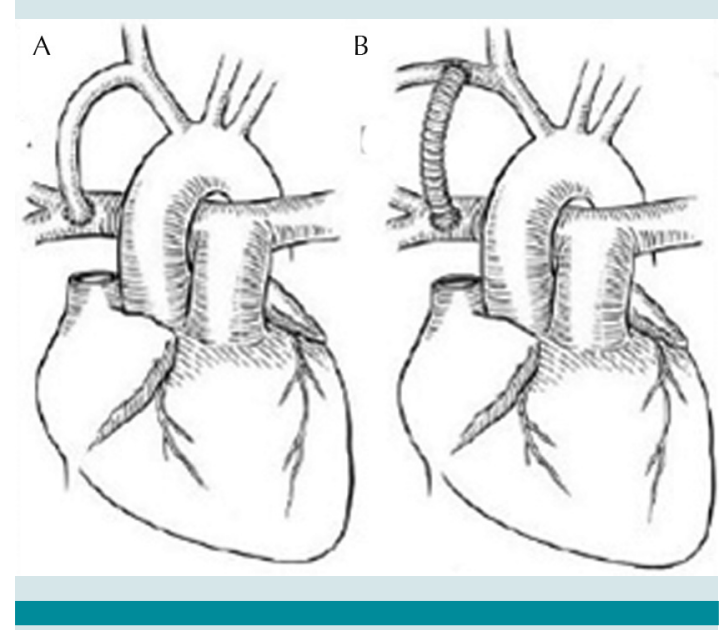

Figura 1. Fístula de Blalock/Taussig. A) Clásica y B) Modificada. el diagnóstico de atresia valvular pulmonar con séptum íntegro y fístula de Blalock-Taussig permeable. Ante el empeoramiento del niño y con la sospecha de oclusión de la fístula se lleva a cateterismo cardiaco con la intención de ampliar la comunicación interauricular y colocación de un stent en la fístula, pero ésta se encontró permeable. El estado del paciente se agrava aún más y fallece durante el cateterismo.

\section{COMENTARIO CARDIOLÓGICO}

\section{Dr. López Terrazas}

La atresia valvular pulmonar con séptum íntegro es una malformación rara que representa de 1 a $3 \%$ de todos los defectos congénitos del corazón. Su presentación es esporádica y no se ha encontrado una predominancia familiar que sea significativa. Es una cardiopatía que habitualmente permite llegar a término el embarazo con un nacimiento sin complicaciones en la mayoría de los casos. Su presentación clínica es con cianosis desde el primer día de vida, con una evolución que progresa rápidamente hacia la dificultad respiratoria y acidosis metabólica. Como substrato morfológico no existe comunicación entre el ventrículo derecho y el árbol arterial pulmonar, por lo que la presencia de un conducto arterioso permeable es imperativo para poder sobrevivir inicialmente con este defecto. Habitualmente hay confluencia de las arterias pulmonares y éstas, así como el tronco pulmonar principal son de dimensiones normales. Ordinariamente se encuentran diferentes grados de hipoplasia del ventrículo derecho, así como de la válvula tricúspide y las fístulas entre el ventrículo derecho y las arterias coronarias se acercan a $40 \%$ de los casos, estando presentes particularmente en los pacientes con hipoplasia severa del ventrículo derecho. Tanto estructural como funcionalmente la hipoplasia de la válvula tricúspide correlaciona directamente con la hipoplasia del ventrículo derecho. El diagnóstico 
definitivo es establecido mediante ecocardiografía bidimensional que muestra la obstrucción de la salida ventricular derecha, así como el tamaño del ventrículo derecho; utilizando técnicas de Doppler color se puede identificar la presencia de fístulas entre el ventrículo derecho y las arterias coronarias.

En cuanto se establece la sospecha, o bien el diagnóstico, se inicia la infusión de prostaglandinas E1 para mantener permeable el conducto arterioso, y una vez estabilizado el paciente proceder al manejo quirúrgico cuya estrategia es diseñada de acuerdo con los hallazgos estructurales aportados por la ecocardiografía y el cateterismo cardíaco.

\section{COMENTARIO HEMODINÁMICO}

\section{Dr. Colín Ortiz}

Se realizó cateterismo cardíaco a solicitud del Servicio de Cardiología por incremento de la cianosis, con desaturación significativa y el hallazgo del segundo estudio ecocardiográfico, donde al parecer había sospecha de obstrucción al flujo sanguíneo de la fístula sistémico-pulmonar. El estudio hemodinámico evidenció que la fístula se encontraba permeable, sin datos de obstrucción con flujo adecuado hacia ambas ramas pulmonares (Figura 2).

En algunos casos hay pacientes que se les ha construido una fístula sistémico-pulmonar y en quienes en un inicio parece clínicamente un funcionamiento adecuado de la misma; sin embargo, hay condiciones sistémicas y/o pulmonares que pueden condicionar alteración del flujo sanguíneo a través de la fístula, sin tener necesariamente obstrucción. Por consiguiente, habrá que tomar en cuenta todas aquellas condiciones que disminuyan la resistencia vascular sistémica como en el presente caso.

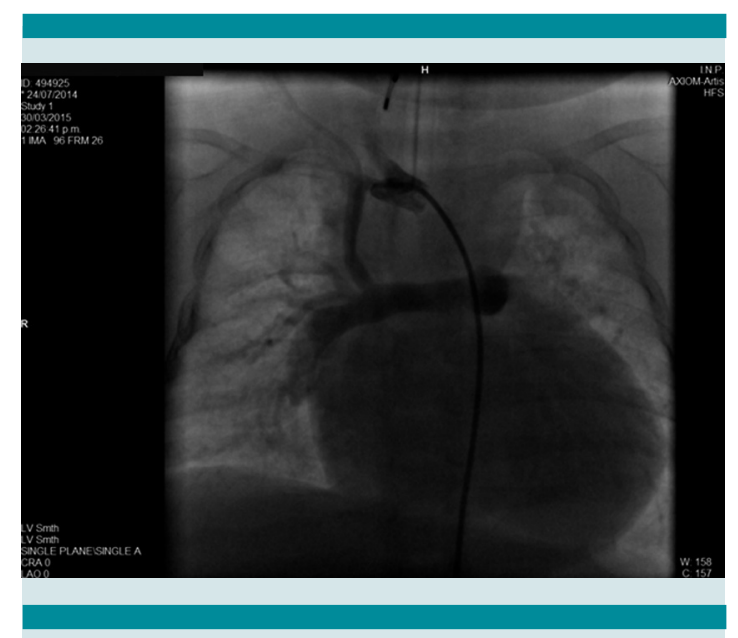

Figura 2. Visualización durante el cateterismo cardíaco de la fístula de Blalock/Taussig modificada permeable.

\section{COMENTARIO QUIRÚRGICO}

\section{Dr. López Terrazas}

El manejo quirúrgico se lleva a efecto en dos o más tiempos, e inicialmente está fundamentado en las características anatómicas y, específicamente en definir el grado de hipoplasia del ventrículo derecho, así como el tamaño del anillo tricuspídeo medido con el score-Z. La primera paliación consiste en la construcción de una fístula de Blalock-Taussig, para asegurar el flujo sanguíneo pulmonar y dependiendo del tamaño del ventrículo derecho, la presencia de sus componentes (porción de entrada, trabecular e infundibular), y si el ventrículo derecho depende de circulación coronaria anómala. Si se considera que el ventrículo tiene posibilidades de crecer y en un futuro tener la capacidad de mantener el gasto pulmonar, se amplía la unión ventrículo arterial con un parche de pericardio autólogo. Durante el seguimiento ulterior la decisión del tipo de estrategia a seguir, dependerá de la rehabilitación del ventrículo derecho y de su capacidad para mantener el gasto pulmonar, lo cual definirá la reparación utilizando dos ventrículos, uno y medio o la creación de una circulación univentricular (Fontan/Kreutzer). 


\section{COMENTARIO ANATOMOPATOLÓGICO}

\section{Dr. López Corella}

El estudio postmortem en este niño documentó e ilustró sobre la patología de base, lo que nos esclareció el desenlace final. El corazón era grande, con el arco aórtico en posición normal a la izquierda y se apreciaba la fístula sistémico pulmonar de Blalock-Taussig de la arteria subclavia a la rama derecha de la arteria pulmonar (Figura 3). La fístula estaba permeable. Las alteraciones cardiacas afectaban las cavidades derechas. La aurícula derecha estaba marcadamente dilatada y recibía a la vena cava superior y a la inferior. El seno coronario estaba moderadamente dilatado, pero no se identificó una vena cava superior izquierda persistente. El

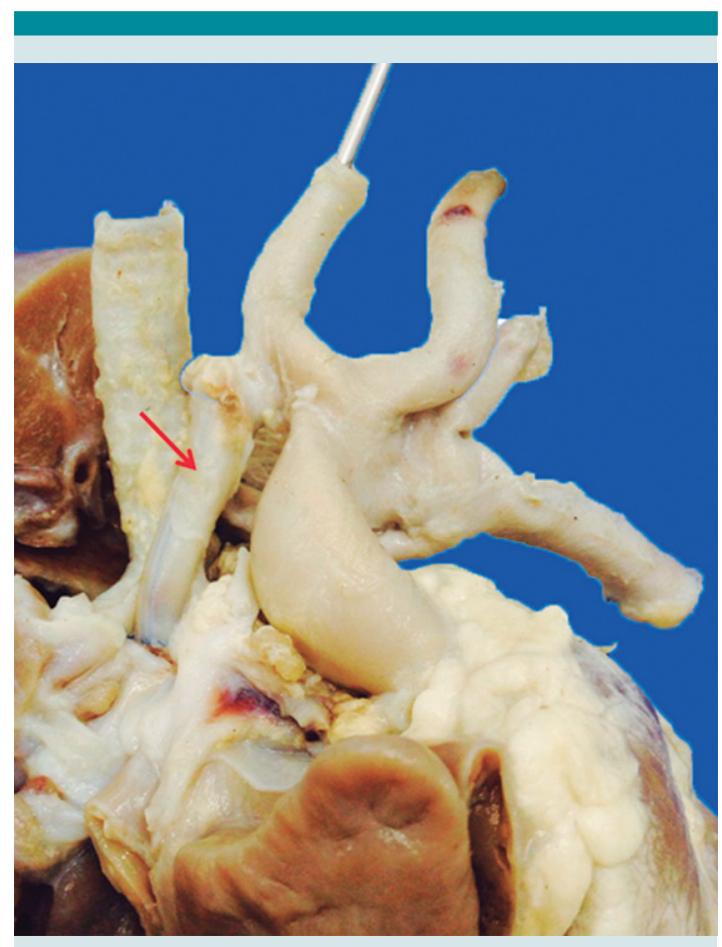

Figura 3. La fístula de Blalock-Taussig, un tubo de material sintético (flecha) conecta la arteria subclavia derecha con la rama derecha de la arteria pulmonar. tabique interauricular mostró un foramen oval estrecho, de $0.4 \mathrm{~cm}$ de diámetro, con un borde circunferencial rígido. La válvula tricúspide es muy anormal, con las valvas fusionadas y con un orificio valvular pequeño y rígido de $0.4 \mathrm{~cm}$ de diámetro (Figura 4). El ventrículo derecho era pequeño, con una profundidad de $0.8 \mathrm{~cm}$ y solo tenía vía de entrada. No parece haber porción trabeculada ni infundíbulo. No existe anillo valvular pulmonar y el tronco de la arteria pulmonar es amplio sin hipoplasia. El conducto arterioso estaba cerrado. El corazón izquierdo es

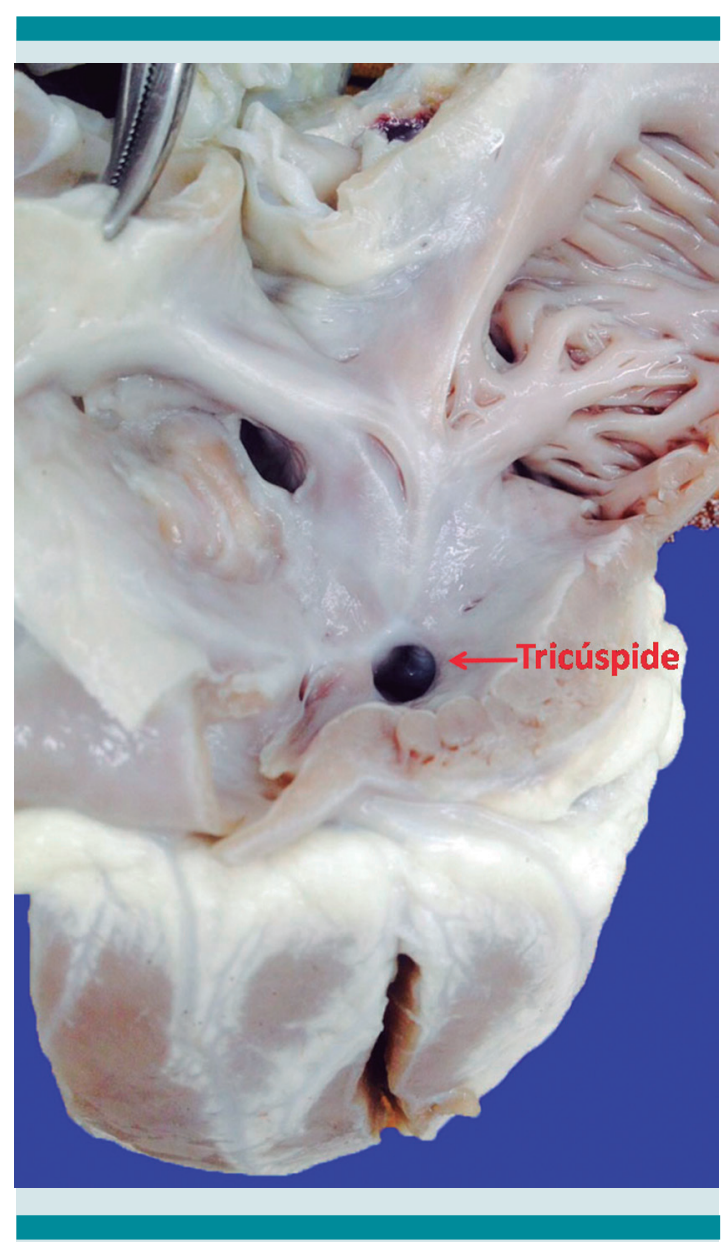

Figura 4. Aurícula derecha dilatada con foramen oval restrictivo $(\mathrm{CI} A)$. La tricúspide es displásica con fusión de valvas, un orificio valvular pequeño conduce a un ventrículo derecho hipoplásico. 
esencialmente normal. El aspecto izquierdo del tabique interventricular era normal y no mostraba comunicación al lado derecho.

En los pulmones sólo se encontraron aislados agrupamientos de macrófagos en algunos alveolos y moderada hiperplasia del tejido linfoide peribronquiolar, seguramente rescoldos del cuadro de neumonía comunitaria que motivó su hospitalización un mes antes de morir y que se resolvió rápidamente.

El cuadro final de este paciente parece haber sido una septicemia de origen probable en un cuadro enteral y que lo condujo a un choque séptico. Los cambios microscópicos en intestino son poco expresivos, como suele suceder en muchas infecciones bacterianas agudas; encontramos hiperplasia linfoide y cambios regenerativos en las criptas de yeyuno e íleon, pero las huellas de la septicemia y choque séptico son evidentes. Tenemos una hepatitis séptica y una esplenitis séptica con hiperemia masiva (Figuras 5 y 6 ), hay hemofagocitosis en hígado y en médula ósea, una colitis hemorrágica segmentaria en ángulo esplénico (Figura 7) y evidencia de una catástrofe circulatoria y de perfusión tisular con una necrosis cortical renal y trombos de fibrina en glomérulos renales.

Un hallazgo inesperado en la autopsia abunda sobre el choque refractario en que murió nuestro paciente. ${ }^{1}$ Ambas glándulas suprarrenales tienen hemorragia masiva que afecta tanto corteza como médula (Figura 8); esta alteración hemorragia masiva adrenal, aunada a colapso cardiovascular en el contexto de un estado séptico grave, configura el síndrome de Waterhouse-Friderischen que, aunque originalmente descrito en asociación a meningococcemia fulminante, en la actualidad se acepta que puede desencadenarse en estados sépticos por otras bacterias, particularmente estafilococo y estreptococo. ${ }^{2,3}$ En este caso, no podemos asignar la causa de la sepsis a un microorganismo en

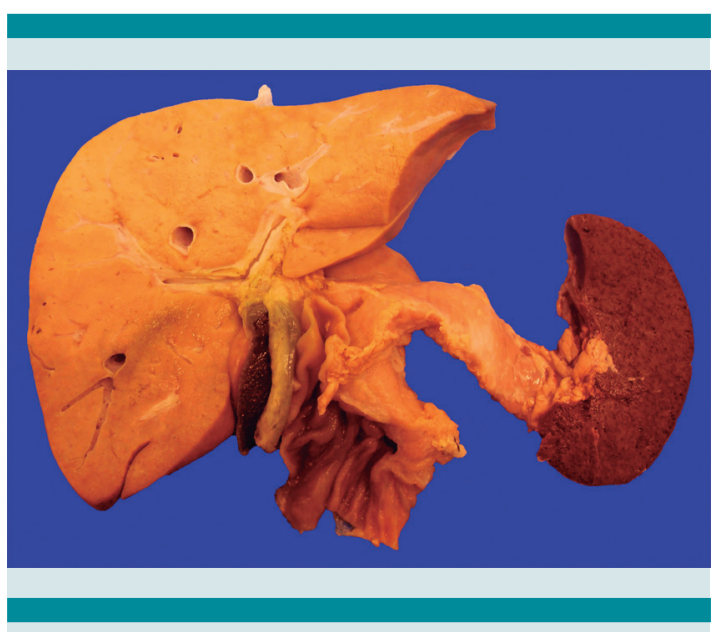

Figura 5. Bloque de hígado, páncreas y bazo. El bazo es de aspecto séptico, hemorrágico y friable.

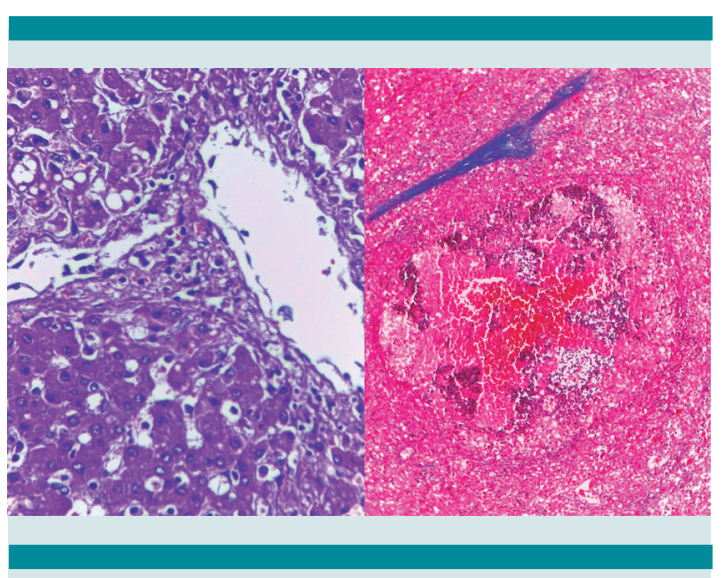

Figura 6. Hepatitis séptica con células inflamatorias en la pared de venas centrales y suprahepáticas (izquierda). Esplenitis séptica con hiperemia masiva y colapso de folículos linfoides (derecha).

particular. No se hicieron cultivos en vida y en nuestros cultivos postmortem crecieron especies bacterianas diversas lo que sugiere una contaminación del procedimiento.

Una lección que nos deja este caso es que ante un paciente en sepsis grave, debe tomarse en cuenta la posible contribución de una falla adrenal aguda que podría indicar el uso pro- 


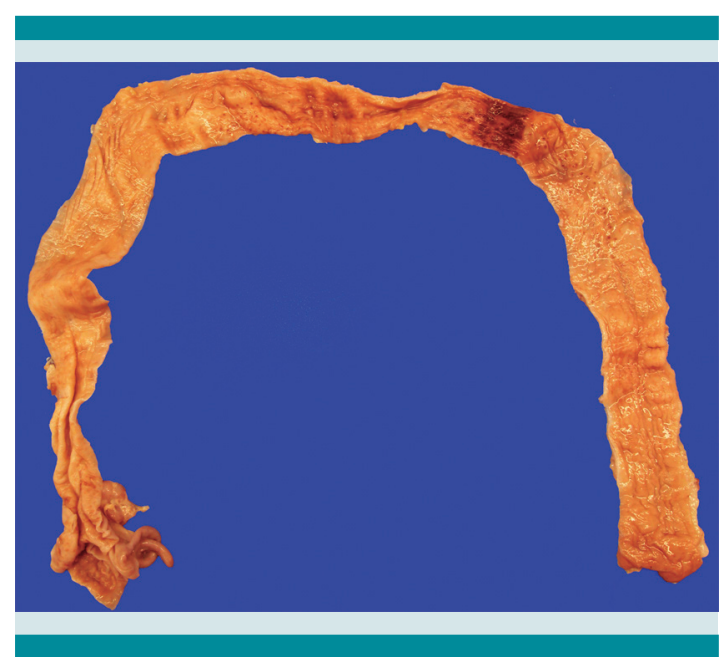

Figura 7. Colon. Colitis isquémica en segmento hemorrágico en ángulo esplénico.

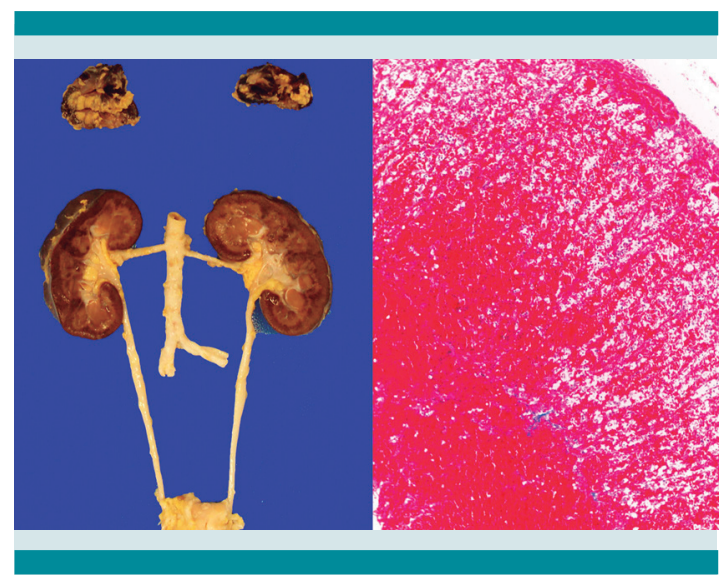

Figura 8. Riñones y adrenales. Hemorragia adrenal masiva bilateral y necrosis cortical renal (izquierda). Aspecto microscópico de la hemorragia masiva adrenal (derecha).

tector de corticoesteroides. Se ha mencionado la aplicación de tomografía axial computada para documentar el aumento de tamaño de las suprarrenales en apoyo al diagnóstico. pero como comentó el Dr. Raúl Calzada en una Sesión Anatomoclínica reciente, aun sin este recurso, el uso de dosis fisiológicas de hidrocortisona podría estar indicado en estos casos. . $^{4-6}$

\section{Diagnósticos anatómicos principales}

Cardiopatía congénita

- Atresia valvular pulmonar con septum íntegro.

- Ventrículo derecho hipoplásico.

- Displasia de válvula tricúspide.

- Foramen oval permeable estrecho.

Fístula de Blalock Taussig, (subclavia derecha a pulmonar derecha) 7 meses.

(Historia de cuadro gastroenteral agudo, 24 horas)

Enteritis subaguda. Colitis isquémica segmentaria.

Septicemia (historia clínica de choque séptico).

- Esplenitis séptica con hiperemia masiva.

- Hepatitis séptica.

Hemorragia adrenal masiva bilateral.

- Síndrome de Waterhouse-Friderischen.

Necrosis cortical renal bilateral.

\section{CONCLUSIÓN}

\section{Dr. López Terrazas}

Aunque el diagnóstico de síndrome de Waterhouse-Friderichsen premortem con sospecha clínica de hemorragia adrenal bilateral es difícil tenerlo en mente, debe sospecharse intuitivamente, ya que es mucho más común que, cuando éste se presenta, contribuya a la mortalidad en el enfermo gravemente comprometido, como es el caso de este paciente. Dado su evolución tan grave durante su corta estancia en nuestra 
institución, y su precaria condición clínica en franca caída libre, el desenlace fatal era inexorable. Sin embargo, en distintos momentos algunas intervenciones pediátricas pudieron haber modificado dicha evolución. No conocemos las particularidades de la atención clínica otorgada en la institución previa, pero cabe decir que aunque la decisión de manejo ambulatorio de un lactante con gastroenteritis aguda sin deshidratación generalmente es una buena práctica clínica en este caso culminó en un desenlace fatal. Vale la pena reflexionar que los lineamientos de atención clínica de padecimientos comunes en pediatría no se deben aplicar con el mismo criterio en poblaciones particularmente vulnerables (i.e. pacientes con cardiopatías congénitas complejas). Por otra parte, la atención de estos pacientes en instituciones de tercer nivel debe poder ofrecer la atención integral y multidisciplinaria a estos pacientes con la suficiente eficiencia para identificar e intervenir oportunamente.

Aunque el mecanismo preciso de hemorragia adrenal es probablemente multifactorial, la vulnerabilidad glandular a la hemorragia es condicionada por factores anatómicos, como un alto flujo sanguíneo de la red arterial con una transición abrupta al plexo capilar. Los capilares en la unión cortico-medular se encuentran en un mayor riesgo durante los períodos de hipotensión y su consecuente lesión por reperfusión.

Las manifestaciones clínicas de hemorragia adrenal varían dependiendo de la cantidad de corteza adrenal involucrada por la hemorragia, su sospecha clínica puede corroborarse mediante tomografía computada e incluso servir ésta como herramienta de seguimiento en la correlación clínico-radiológica. El empleo de antibióticos es considerado el tratamiento principal ante una infección de cualquier organismo virulento. La administración de glucocorticoides sin tener la evidencia documentada de insufi- ciencia o hemorragia adrenal aún está en debate; sin embargo, si se identifica un paciente con un perfil de alto riesgo, parece razonable iniciar de inmediato la administración de glucocorticoides, mientras se confirma el diagnóstico de hemorragia adrenal.

En lo que respecta a la evolución en el manejo de este paciente, de no haberse presentado el cuadro infeccioso gastrointestinal, con el consecuente estado de choque séptico agravado por la insuficiencia adrenal aguda, la reparación ulterior hubiera dependido de la rehabilitación morfológica y funcional del ventrículo derecho hipoplásico para llegar a una reparación biventricular, ventrículo uno y medio o bien una circulación univentricular tipo Fontan/Kreutzer.

PALABRAS CLAVE: atresia pulmonar con septum integro, síndrome de Waterhouse-Friederichsen, hemorragia adrenal bilateral, insuficiencia adrenal.

KEYWORDS: pulmonary atresia with intact ventricular septum; Waterhouse- Friderichsen syndrome; bilateral adrenal hemorrhage; adrenal insufficiency

\section{REFERENCIAS}

1. Edwards OM. Adrenal apoplexy - the silent killer. J R Soc Med. 1993;86:1-2.

2. Hamilton D, Harris MD, Foweraker J, Gresham GA. Waterhouse-Friderischen syndrome as a result of nonmeningococcal infection. J Clin Pathol. 2004;57:208-209.

3. Adem PV, Montgomery CP, Husain AN. Staphylococcus aureus sepsis and the Waterhouse-Friderischen syndrome in children. N Eng J Med 2005;353:1245-1251.

4. Calzada León R. Comentario en: González Zamora JF, Ridaura Sanz C. Sesión Anatomoclínica del jueves 26 de noviembre, 2015. Instituto Nacional de Pediatría. México.

5. Hatherill M, Tibby SM, Hilliard R y otros. Adrenal insufficiency in septic shock. Arch Dis Child. 1999;80:51-55.

6. Brierley J, Carcillo JA, Choong K. Clinical practice parameters for hemodynamic support of pediatric and neonatal septic shock: 2007 update frm the American College of Critical Care Medicine. Crit Care Med. 2009;37:666-688. 